\title{
Peroxisome proliferator-activated receptor $\beta / \delta$ regulates cerebral vasospasm after subarachnoid hemorrhage via modulating vascular smooth muscle cells phenotypic conversion
}

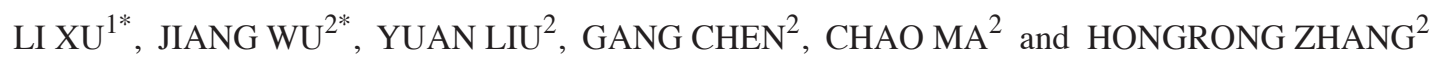 \\ ${ }^{1}$ Intensive Care Unit of Department of Anesthesiology; ${ }^{2}$ Department of Neurosurgery, \\ The First Affiliated Hospital of Soochow University, Suzhou, Jiangsu 215026, P.R. China
}

Received June 11, 2021; Accepted September 27, 2021

DOI: $10.3892 / \mathrm{mmr} .2021 .12500$

\begin{abstract}
Cerebral vasospasm (CVS) is a common complication of subarachnoid hemorrhage (SAH) with high deformity rates and cerebral vascular smooth muscle cells (VSMCs) phenotypic switch is considered to be involved in the regulation of CVS. However, to the best of the authors' knowledge, its underlying molecular mechanism remains to be elucidated. Peroxisome proliferator-activated receptor $\beta / \delta(\operatorname{PPAR} \beta / \delta)$ has been demonstrated to be involved in the modulation of vascular cells proliferation and maintains the autoregulation function of blood vessels. The present study investigated the potential effect of PPAR $\beta / \delta$ on CVS following SAH. A model of SAH was established by endovascular perforation on male adult Sprague-Dawley rats, and the adenovirus PPAR $\beta / \delta$ (Ad-PPAR $\beta / \delta$ ) was injected via intracerebroventricular administration prior to SAH. The expression levels of phenotypic markers $\alpha$-smooth muscle actin and embryonic smooth muscle myosin heavy chain were measured via western blotting or immunofluorescence staining. The basilar artery diameter and vessel wall thickness were evaluated under fluorescence microscopy. SAH grade, neurological scores, brain water content and brain swelling were measured to study the mechanisms of PPAR $\beta / \delta$ on vascular smooth muscle phenotypic transformation. It was revealed that the expression levels of synthetic proteins were upregulated in rats with SAH and this was accompanied by CVS. Activation of PPAR $\beta / \delta$ using Ad-PPAR $\beta / \delta$ markedly upregulated the contractile proteins
\end{abstract}

Correspondence to: Dr Chao Ma or Dr Hongrong Zhang, Department of Neurosurgery, The First Affiliated Hospital of Soochow University, 899 Pinghai Road, Suzhou, Jiangsu 215026, P.R. China

E-mail:machaoss@163.com

E-mail: zhanghr0521@163.com

${ }^{*}$ Contributed equally

Key words: phenotypic switch, peroxisome proliferator-activated receptor $\beta / \delta$, subarachnoid hemorrhage, vascular smooth muscle cell, cerebral vasospasm elevation, restrained the synthetic proteins expression and attenuated $\mathrm{SAH}$-induced CVS by regulating the phenotypic switch in VSMCs at $72 \mathrm{~h}$ following SAH. Furthermore, the preliminary study demonstrated that PPAR $\beta / \delta$ downregulated ERK activity and decreased the expression of phosphorylated (p-)ETS domain-containing protein Elk-1 and p-p90 ribosomal S6 kinase, which have been demonstrated to serve an important role in VSMC phenotypic change. Additionally, it was revealed that Ad-PPAR $\beta / \delta$ could positively improve CVS by ameliorating the diameter of the basilar artery and mitigating the thickness of the vascular wall. Furthermore, subsequent experiments demonstrated that Ad-PPAR $\beta / \delta$ markedly reduced the brain water content and brain swelling and improved the neurological outcome. Taken together, the present study identified PPAR $\beta / \delta$ as a useful regulator for the VSMCs phenotypic switch and attenuating CVS following $\mathrm{SAH}$, thereby providing novel insights into the therapeutic strategies of delayed cerebral ischemia.

\section{Introduction}

In the past few years, cerebral vasospasm (CVS) has been considered to be one of the complications leading to severe neurological dysfunction after subarachnoid hemorrhage (SAH). Numerous studies have explored the mechanisms of CVS following SAH and have made several discoveries (1-4). However, the pathophysiological mechanism remains elusive and no effective treatment for CVS exists at present (5). Previous studies have revealed that certain pathological processes, such as smooth muscle cell contraction resulting from spasmogenic substances generated during the lysis of the subarachnoid blood wall and endothelial damage, are associated with the pathogenesis of CVS (6-8). As has been previously reported, the phenotypic transformation of vascular smooth muscle cells (VSMCs) occurs in the vessel wall of CVS (9-11) and which is considered to contribute to the CVS following SAH.

VSMCs retain extraordinary plasticity and possess the quality of invertible phenotypic transition; they can convert from the contractile phenotype to the synthetic phenotype in response to various cellular stimulator substances $(12,13)$. Synthetic phenotype VSMCs can increase their rates of proliferation and oversynthesis and excretion of extracellular matrix, 
which are the pivotal events of vascular wall thickening and vascular lumen stenosis, eventually leading to dysfunction of vascular autoregulation and CVS $(14,15)$. CVS resulting from phenotypic transformation of VSMCs impairs the cerebral blood flow distribution (16) and leads to a delayed ischemic neurological deficit. Notably, the phenotype of VSMCs is distinguished mainly based on specific proteins; $\alpha$-smooth muscle actin ( $\alpha$-SMA) is chiefly expressed in the contractile phenotype and embryonic smooth muscle myosin heavy chain (SMemb) is an accurate marker of synthetic VSMCs $(13,17)$.

Peroxisome proliferator-activated receptor $\beta / \delta(\operatorname{PPAR} \beta / \delta)$ has been characterized as anti-inflammatory and antiapoptotic and can modulate vascular cells proliferation (18). In addition, it exerts neuroprotective effects on acute and chronic injury of the central nervous system $(19,20)$. A previous study reported that activation of PPAR $\beta / \delta$ can efficiently attenuate the inflammation of VSMCs and decrease the release of inflammatory factors (21), which provides a potential line of inquiry for vascular diseases of the central nervous system. Phosphorylation of the ERK1/2 signaling pathway induces the activation of intracellular signals via the phosphorylation of regulatory targets, including extracellular proteins and transcription factors $(22,23)$. ETS domain-containing protein Elk-1 (Elk-1) and p90 ribosomal S6 kinase (p90RSK) are downstream targets of ERK1/2, which are phosphorylated by ERK1/2 and associated with gene transcription, protein synthesis and proliferation $(24,25)$. There is compelling evidence that subsequent activation of the ERK1/2 signaling pathway exerts an efficiently effect in modulating VSMC proliferation and migration (26). However, to the best of the authors' knowledge, no studies have investigated the function and possible mechanisms of PPAR $\beta / \delta$ in VSMCs phenotypic modulation, which contributes to CVS following SAH.

\section{Materials and methods}

Animals and SAH model establishment. The experiments were performed as shown in the schematic (Fig. 1). All experimental procedures were approved by the Animal Experiments Ethic Committee at The First Affiliated Hospital of Soochow University (Suzhou, China; approval no. 2018-094) and were performed in accordance with the Laboratory Animal Guidelines for ethical review of animal welfare (standard no. GB/T 35892-2018) (27). A total of 192 male Sprague-Dawley (SD) rats purchased from the Animal Experiment Center of Soochow University (age, 6-8 weeks; weight, 300-350 g) were used in the present study and the endovascular perforation model of SAH was performed as reported previously (28). Briefly, anesthesia was induced with $5 \%$ isoflurane using a facemask and maintained with $1.5 \%$ isoflurane. Subsequently, the rats were fixed in the supine position. The internal carotid artery (ICA) and external carotid artery (ECA) were carefully separated. Afterwards, a sharpened 4-0 monofilament nylon suture was inserted into the middle cerebral artery through the ICA and gently pushed forward to pierce the vessel. The thread was drawn out to restore blood supply. Sham operated rats received the same procedure except for perforation. Following surgery, the animals were kept in an incubator heated at $36^{\circ} \mathrm{C}$ for $1 \mathrm{~h}$. The rats were housed under controlled environmental conditions (12-h light/dark cycle; $23 \pm 1^{\circ} \mathrm{C}, 55 \pm 5 \%$ relative humidity) with free access to water and food. Body weight and body temperature was determined daily as a sensitive indicator for their well-being. Likewise, neurological deficits were assessed on a daily basis using the previously described modified Garcia scale (29). In the present study, rats clearly in pain, showing signs of severe and enduring distress, or characterized as moribund were humanely sacrificed rather than allowed to survive to the end of the scheduled study (at $72 \mathrm{~h}$ after SAH). Animals were euthanized at $72 \mathrm{~h}$ after SAH when a loss of more than $20 \%$ baseline body weight occurred or the following qualitative humane endpoint criteria were observed during inspection: Paralysis with absence of spontaneous movement, severe ataxia or loss of postural reflexes, epileptic seizures, coma, reduction of general health status with reduced grooming or refusal of food intake. Rats were euthanized at $72 \mathrm{~h}$ after SAH by deep (5\%) isoflurane followed by cardiac perfusion with $30 \mathrm{ml}$ phosphate-buffered saline, decapitation was implemented under deep anesthesia after cardiac perfusion and the brains were rapidly removed.

The basal cistern was divided into six segments and scored from 0-3 points by a blinded observer according to the amount of subarachnoid blood. Each segment was allotted a grade between 0 and 3 depending on the amount of subarachnoid blood clot in the segment as follows: i) Grade 0, no subarachnoid blood; ii) 1, minimal subarachnoid blood; iii) 2, moderate blood clot with recognizable arteries; and iv) 3, blood clot obliterating all arteries within the segment. The total score from all six segments represented the severity of the SAH (29). Rats who received a score $<7$ were excluded from the present study. As in previous studies, modified Garcia scale (score, 3-18; Table I) (29) and beam balance (score, 0-4) (30) were used to assess neurological impairment.

Adenoviruses administration. A total of 36 rats were randomly divided into six groups with six rats in each group as follows: i) Sham; ii) $6 \mathrm{~h}$ after SAH; iii) $12 \mathrm{~h}$ after SAH; iv) $24 \mathrm{~h}$ after $\mathrm{SAH}$; v) $72 \mathrm{~h}$ after SAH; and vi) 5 days after SAH. Western blotting was used to detect the expression of $\alpha$-SMA and SMemb in the cerebral vessels of each group at different time points.

Adenoviruses PPAR $\beta / \delta(A d-P P A R \beta / \delta$ ) and adenoviruses green fluorescent protein (Ad-GFP; as a control for Ad-PPAR $\beta / \delta$ ) (Shanghai GeneChem Co., Ltd.) were diluted to $1.3 \times 10^{10} \mathrm{pfu} / \mathrm{ml}$ in enhanced transfection solution (Shanghai GeneChem Co., Ltd.) before use. According to a previous report (31), a small hole was drilled on the skull according to the coordinates of $1.0 \mathrm{~mm}$ posterior of bregma and $2.0 \mathrm{~mm}$ lateral of sagittal suture. A total of $10 \mu \mathrm{l}$ diluted Ad-PPAR $\beta / \delta$ or Ad-GFP were slowly injected into the lateral ventricle on the 6th days before SAH (32) through the hole, at a depth of $4.0 \mathrm{~mm}$. At $72 \mathrm{~h}$ after $\mathrm{SAH}$, the rats were randomly divided into the following four groups: i) Sham; ii) SAH + Ad-GFP; iii) $\mathrm{SAH}+\mathrm{Ad-PPAR} \beta / \delta$; and iv) $\mathrm{SAH}$.

Brain water content. Rats were euthanized at $72 \mathrm{~h}$ after SAH by deep (5\%) isoflurane followed by cardiac perfusion with $30 \mathrm{ml}$ phosphate-buffered saline, decapitation was implemented under deep anesthesia after cardiac perfusion and the brains were removed rapidly. Brain water content was measured using the wet/dry method (33). Briefly, brains 


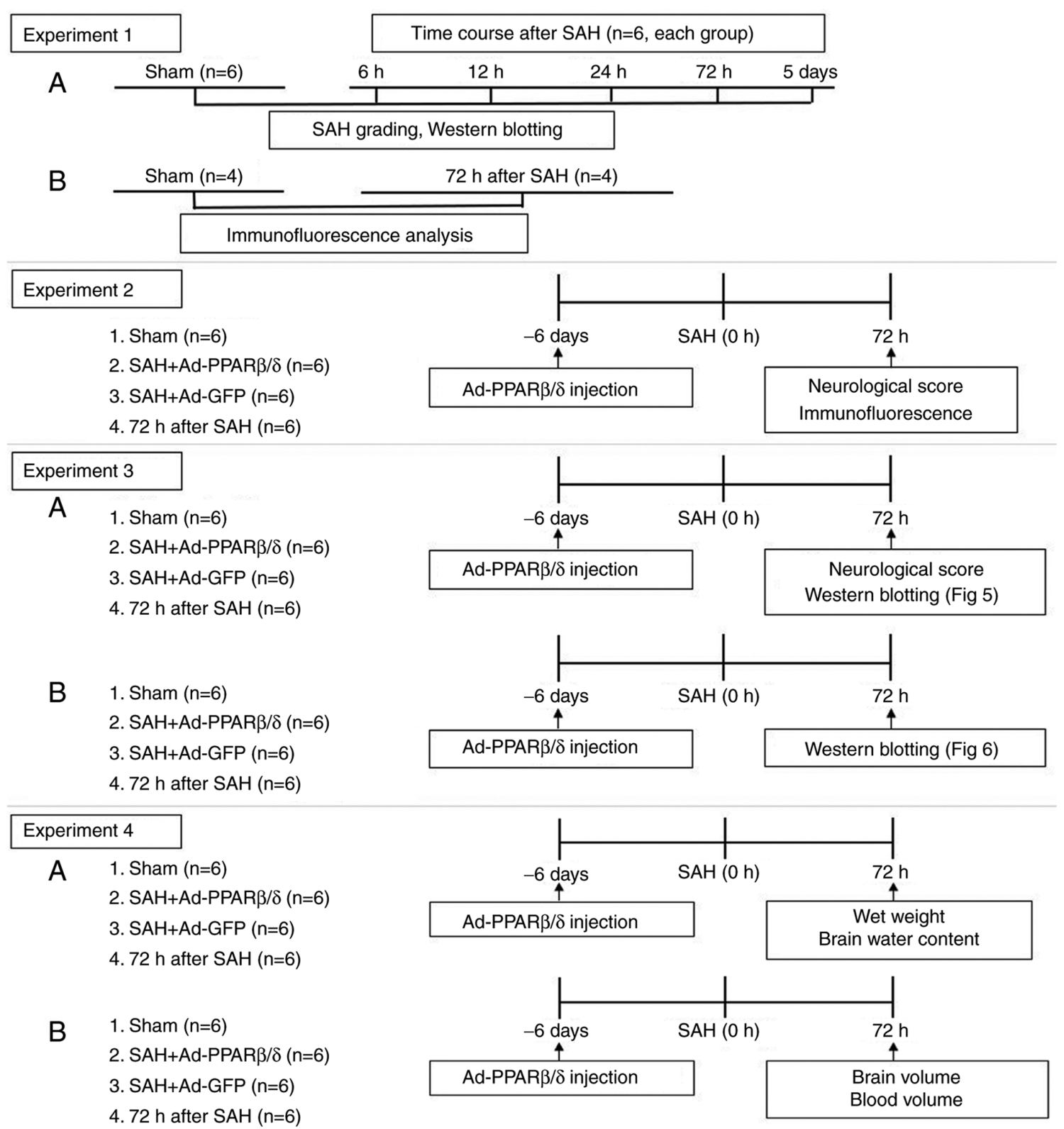

Figure 1. Schematic demonstration of overall experimental process. SAH, subarachnoid hemorrhage; PPAR $\beta / \delta$, peroxisome proliferator-activated receptor $\beta / \delta$; Ad, adenovirus; GFP, green fluorescent protein.

were removed from rats at $72 \mathrm{~h}$ after $\mathrm{SAH}$ and divided into four parts: i) Right hemisphere; ii) left hemisphere; iii) brain stem; and iv) cerebellum. Each part was weighed (wet weight) immediately on a precise electronic scale and then placed into the oven for drying for $48 \mathrm{~h}$ at $105^{\circ} \mathrm{C}$ (dry weight) and the percentage of brain water content was calculated as follows: [(wet weight-dry weight)/wet weight] x100\%.

Brain volume and cerebral blood volume. Rats were euthanized at $72 \mathrm{~h}$ after SAH by deep (5\%) isoflurane followed by cardiac perfusion with $30 \mathrm{ml}$ phosphate-buffered saline, decapitation was implemented under deep anesthesia after cardiac perfusion and the brains were removed rapidly. Brain volume was measured as following previously described (33). Briefly, plastic $10 \mathrm{ml}$ vials containing $5.0 \mathrm{ml}$ of saline were marked equally to the level of liquid by using ultrathin marker. After meticulous clot removal, the brain was put into the vial and the increased level of liquid was marked and the brain volume was measured by titrated saline infusion within marked levels. Vertical position of vials upon measurements was maintained. Cerebral blood volume was measured as previously described $(33,34)$. The brain was then extracted and phosphate-buffered saline (PBS) was added to it to reach a total volume of $3 \mathrm{ml}$. This solution was homogenized for $30 \mathrm{sec}$. After homogenization, ultrasound (20 KHz, ice bath) was applied for $1 \mathrm{~min}$ to lyse erythrocytic membranes and then centrifuged for $30 \mathrm{~min}\left(11,000 \mathrm{x} \mathrm{g}, 4^{\circ} \mathrm{C}\right)$. Several (minimum of three) samples of the $100 \mu 1$ supernatant were added to $400 \mu 1$ Drabkins reagent (Sigma-Aldrich; Merck KGaA) and allowed to stand for $15 \mathrm{~min}$ at room temperature. Finally, optical density was measured and recorded at $540 \mathrm{~nm}$ with a spectrophotometer. Then, additional hemispheric brain tissue was obtained from normal rats subjected to complete cardiac perfusion. Incremental volumes $(0,2,4,8,16$ and $32 \mu \mathrm{l})$ of 
Table I. Neurological evaluation of animals at $72 \mathrm{~h}$ after SAH.

Score

\begin{tabular}{|c|c|c|c|c|}
\hline Test & 0 & 1 & 2 & 3 \\
\hline $\begin{array}{l}\text { Spontaneous activity } \\
\text { (in cage for } 5 \mathrm{~min} \text { ) }\end{array}$ & No movement & Barely moves position & $\begin{array}{l}\text { Moves but does not } \\
\text { approach at least three } \\
\text { sides of cage }\end{array}$ & $\begin{array}{l}\text { Moves and } \\
\text { approaches at least } \\
\text { three sides of cage }\end{array}$ \\
\hline $\begin{array}{l}\text { Spontaneous movements } \\
\text { of all limbs }\end{array}$ & No movement & $\begin{array}{l}\text { Slight movement of } \\
\text { limbs }\end{array}$ & $\begin{array}{l}\text { Moves all limbs } \\
\text { but slowly }\end{array}$ & $\begin{array}{l}\text { Move all limbs same } \\
\text { as pre-SAH }\end{array}$ \\
\hline $\begin{array}{l}\text { Movements of forelimbs } \\
\text { (outstretching while held } \\
\text { by tail) }\end{array}$ & No outreaching & Slight outreaching & $\begin{array}{l}\text { Outreach is limited and } \\
\text { less than pre-SAH }\end{array}$ & $\begin{array}{l}\text { Outreach same } \\
\text { as pre-SAH }\end{array}$ \\
\hline Climbing wall of wire cage & N/A & Fails to climb & Climbs weakly & Normal climbing \\
\hline $\begin{array}{l}\text { Reaction to touch on both } \\
\text { side of trunk }\end{array}$ & N/A & No response & Weak response & Normal response \\
\hline Response to vibrissae touch & N/A & No response & Weak response & Normal response \\
\hline
\end{tabular}

The maximum attainable score was 18 . SAH, subarachnoid hemorrhage; N/A, not applicable.

homologous blood which were obtained from a cardiac puncture after deep (5\%) isoflurane anesthesia were added to each hemispheric sample with PBS to reach a total volume of $3 \mathrm{ml}$ and then the above procedures completed. These procedures yielded a linear relationship between hemoglobin concentrations in brain tissue and blood volume. Using the equation of the best-fitting linear regression line from these data, the blood volume of SAH rats was determined based on absorbance readings.

Immunofluorescence. Immunofluorescence staining was performed using fixed frozen sections. At $72 \mathrm{~h}$ after $\mathrm{SAH}$, deep anesthesia of rats was induced and maintained with 5\% isoflurane, followed by cardiac perfusion with $30 \mathrm{ml}$ phosphate-buffered saline. Decapitation was implemented under deep anesthesia after cardiac perfusion and the brains were rapidly removed. All fixed frozen sections were incubated at $4^{\circ} \mathrm{C}$ overnight with primary antibodies: Mouse anti- $\alpha$-SMA (Abcam; 1:200; cat. no. ab7817) and rabbit anti-SMemb (Abcam; 1:200; cat. no. ab230823) antibodies followed by incubation with secondary antibodies (Abbkine Scientific Co., Ltd.; 1:200; cat. nos. A22110 and A24421) for $2 \mathrm{~h}$ at room temperature. Fluorescence images were effectively captured using a fluorescence microscope (Leica Microsystems $\mathrm{GmbH}$ ). As reported previously $(35,36)$, Image-Pro Plus v.6.0 software (Media Cybernetics, Inc.) was used to measure the thickness of the basilar artery and lumen diameter.

Western blotting. Rats were euthanized at $72 \mathrm{~h}$ after $\mathrm{SAH}$ by deep (5\%) isoflurane, decapitation was implemented under deep anesthesia and the brains were rapidly removed. With the aid of a microscope, the basilar arteries and circle of Willis arteries were separated out of each brain, cleared of connective tissue and snap frozen in liquid nitrogen until homogenization in RIPA buffer (Beyotime Institute of Biotechnology) containing protease and phosphatase inhibitors. The total protein concentration was measured using a BCA Protein Assay Reagent (Beyotime Institute of Biotechnology). The proteins $(25 \mu \mathrm{g})$ were separated via $10 \%$ SDS-PAGE (Beyotime Institute of Biotechnology), and then transferred onto a PVDF membrane (Bio-Rad Laboratories, Inc.). The membranes were then blocked with 5\% skimmed milk in Tris-buffered saline containing $0.1 \%$ Tween-20 (Beijing Solarbio Science \& Technology Co., Ltd.) for $1 \mathrm{~h}$ at room temperature, and incubated overnight at $4^{\circ} \mathrm{C}$ with primary antibodies against $\alpha$-SMA (Abcam; 1:200; cat. no. ab7817), SMemb (Abcam; 1:200; cat. no. ab230823), p-ERK (Cell Signaling Technology, Inc.; 1:2,000; cat. no. 4370), ERK (Cell Signaling Technology, Inc.; 1:1,000; cat. no. 9102), p-Elk-1 (Cell Signaling Technology, Inc.; 1:1,000; cat. no. 9186), Elk-1 (Cell Signaling Technology, Inc.; 1:1,000; cat. no. 9182), p-p90RSK (Cell Signaling Technology, Inc.; 1:1,000; cat. no. 11989), p90RSK (Cell Signaling Technology, Inc.; 1:1,000; cat. no. 9355) and GAPDH (ProteinTech Group, Inc.; 1:2,000; cat. no. 60004-1-Ig). The membranes were subsequently incubated with relative horseradish peroxidase-conjugated $\operatorname{IgG}(1: 1,000$; Beyotime Institute of Biotechnology; cat. no. A0216) for $1 \mathrm{~h}$ at $37^{\circ} \mathrm{C}$ and visualized by using an ECL kit (Beyotime Institute of Biotechnology; cat. no. P0018FS) through X-ray film. Optical densities of these bands were quantified using Quantity One Software (v4.6.2; Bio-Rad Laboratories, Inc.). GAPDH was used as an internal reference.

Statistical analysis. All experiments were repeated at least three times. All data are presented as the mean \pm standard deviation (SD) and were analyzed using SPSS 19.0 software (IBM Corp.). Fisher's exact test was used to compare the mortality rates among groups. Significance of differences in neurologic scores was analyzed by Kruskal-Wallis test followed by Dunn's post hoc test. Mean group values were assessed using one-way analysis of variance followed by Tukey's post hoc test for multiple comparisons. $\mathrm{P}<0.05$ was considered to indicate a statistically significant difference. 


\section{Results}

Mortality and SAH severity. A total of 192 SD rats were used in this work and 28 animals succumbed due to severe SAH reactions within $24 \mathrm{~h}$ following surgery; in the end, 164 rats were effectively applied to subsequent experiments. The overall mortality of SAH in the present study was $14.58 \%$ (28 out of 192 rats). A similar death rate is reported in a previous study (37). The average SAH grading score was not significantly different among the 6,12, 24 and $72 \mathrm{~h}$ groups after $\mathrm{SAH}$. The average SAH grading declined to some extent at 5 days following SAH compared with $6 \mathrm{~h}$ after SAH (Fig. 2).

Expression profile of marker proteins of phenotypic change of VSMCs. Our previous study revealed that the hemoglobin could induce a cerebral VSMCs switch from the contractile to synthetic phenotype in vitro (38). The present study first investigated whether cerebral VSMCs would respond to SAH in vivo. As expected, the western blotting results demonstrated that the $\alpha$-SMA expression decreased as early as at $6 \mathrm{~h}$ and was significantly decreased at $72 \mathrm{~h}$, whereas it exhibited no significant difference at 5 days compared with Sham group (Fig. 3A and B). In addition, SMemb expression variations occurred as early as at $6 \mathrm{~h}$ and it was significantly increased at $72 \mathrm{~h}$ (Fig. 3C) compared with the expression levels in the Sham group. This coincided with the time of CVS. According to this preliminary data, the time point of $72 \mathrm{~h}$ (time of maximal SMemb expression) was selected to perform the subsequent experiments.

To further confirm the changes of the expression profile and morphology of cerebral vessels, double immunofluorescence was performed to analyze $\alpha$-SMA and SMemb expression and localization in the basilar artery. As expected, the results demonstrated that the SMemb fluorescence intensity was increased on the wall of the basilar artery at $72 \mathrm{~h}$ after $\mathrm{SAH}$, whereas the $\alpha$-SMA fluorescence intensity was decreased at $72 \mathrm{~h}$ after SAH (Fig. 3D).

Overexpression of $P P A R \beta / \delta$ protein induced by $A d-P P A R \beta / \delta$ improves neurological deficits and attenuates $C V S$ at $72 \mathrm{~h}$ after $S A H$. To further ascertain whether PPAR $\beta / \delta$ could attenuate the VSMCs phenotypic transformation following $\mathrm{SAH}$ in vivo, additional experiments were conducted in which $\mathrm{PPAR} \beta / \delta$ protein was overexpressed using intracerebroventricular injection of Ad-PPAR $\beta / \delta$ at day 6 before $\mathrm{SAH}$.

Consistent with the results in Fig. 3D, immunofluorescence analysis (Fig. 4A) of the basilar artery revealed that $\alpha$-SMA immunoreactivity decreased at $72 \mathrm{~h}$ and this was accompanied by an increase in SMemb immunoreactivity. However, the change in immunoreactivity could be reversed by Ad-PPAR $\beta / \delta$. With the use of Ad-PPAR $\beta / \delta$, the immunoreactivity of $\alpha$-SMA was notably enhanced in the $\mathrm{SAH}+\mathrm{Ad}-\mathrm{PPAR} \beta / \delta$ group. As shown in Fig. 4B, rats in the SAH and SAH + Ad-GFP groups exhibited severe neurological impairments compared with rats in the sham and SAH + Ad-PPAR $\beta / \delta$ groups. Furthermore, the histopathological alterations, including the thickness of the vascular wall and lumen stenosis in the basilar artery, were significantly ameliorated by Ad-PPAR $\beta / \delta$ (Fig. 4C).

ERK signaling pathway is involved in PPAR $\beta / \delta$ suppression of phenotypic modulation of VSMCs and CVS in rats at $72 \mathrm{~h}$

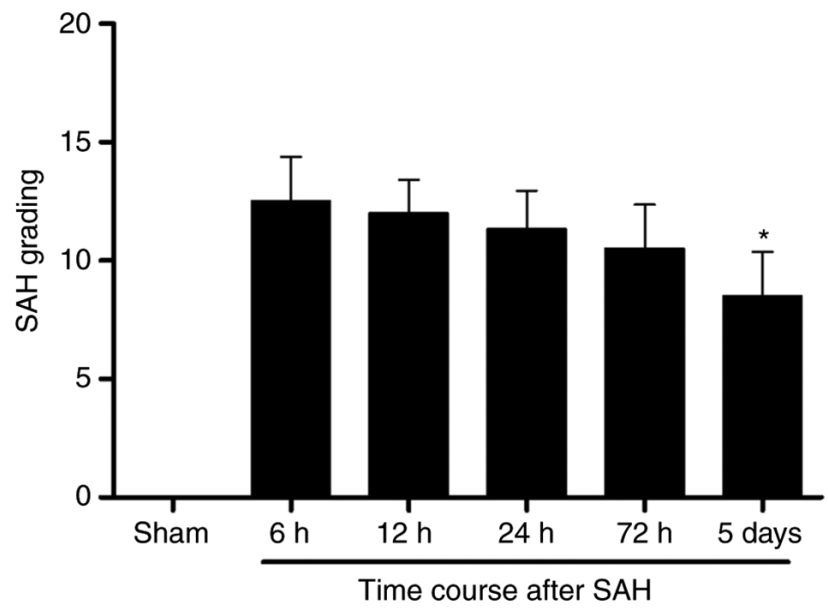

Figure 2. SAH grading of rats in each group. The average SAH grading score was not significantly different among the $6,12,24$ and $72 \mathrm{~h}$ groups. The average SAH grading declined to some extent at 5 days after SAH. $n=6$ rats per group. ${ }^{*} \mathrm{P}=0.026$ vs. $6 \mathrm{~h}$. $\mathrm{SAH}$, subarachnoid hemorrhage.

after $S A H$. It was hypothesized that the effect of PPAR $\beta / \delta$ on the phenotypic switch of VSMCs was regulated by the ERK signaling pathway. Therefore, the levels of p-ERK was first detected using western blotting at $72 \mathrm{~h}$ after SAH. As shown in Fig. 5A, activation of the ERK signaling pathway was demonstrated by increased levels of p-ERK following SAH. Furthermore, prior injection of Ad-PPAR $\beta / \delta$ similarly administered into cerebral ventricles significantly increased PPAR $\beta / \delta$ and $\alpha$-SMA expression, while decreasing the levels of p-ERK and SMemb following SAH (Fig. 5A-E) and this was accompanied by an improvement in neurological functions (Fig. 5F). Combined, these data revealed that the ERK signaling pathway served a role in PPAR $\beta / \delta$ modulating phenotypic transformation of VSMCs and attenuating CVS following SAH.

PPAR $\beta / \delta$ inhibits cerebral VSMCs phenotypic switch and attenuates CVS via suppression of $p$-Elk-1 and p-p90RSK expression. Elk-1 and p90RSK are downstream targets of ERK and can be activated by phosphorylation of ERK1/2 and JNK MAPKs, which are essential for gene regulation, cell migration and proliferation, and protein synthesis (24-26).

In the present study, the expression of p-Elk-1 was significantly increased at $72 \mathrm{~h}$ after SAH. However, the expression p-Elk-1 was significantly downregulated by pretreatment of rats with Ad-PPAR $\beta / \delta$ (Fig. 6A and B). As with p-Elk-1, the expression of p-p90RSK was increased at $72 \mathrm{~h}$ after $\mathrm{SAH}$ and these were markedly downregulated by addition of Ad-PPAR $\beta / \delta$ (Fig. $6 \mathrm{C}$ and D). These results indicated that $\mathrm{PPAR} \beta / \delta$ maintained the contractile phenotype of VSMCs and attenuated CVS by restraining the expression of p-Elk-1 and p-p90RSK.

Ad-PPAR $\beta / \delta$ ameliorates brain swelling and brain edema. Brain swelling was assessed based on the wet brain weight, brain volume and cerebral blood volume. To ascertain the effect of PPAR $\beta / \delta$ on brain swelling, Ad-PPAR $\beta / \delta$ was administrated at 6 days before SAH. In the present study, brain wet weight and brain volume were significantly increased at $72 \mathrm{~h}$ 
A

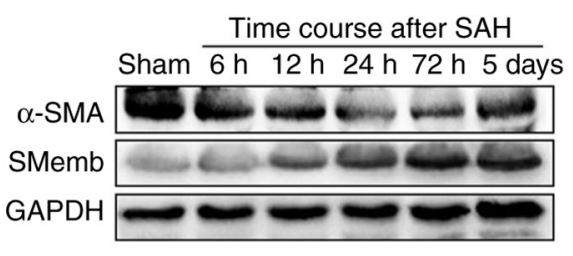

D
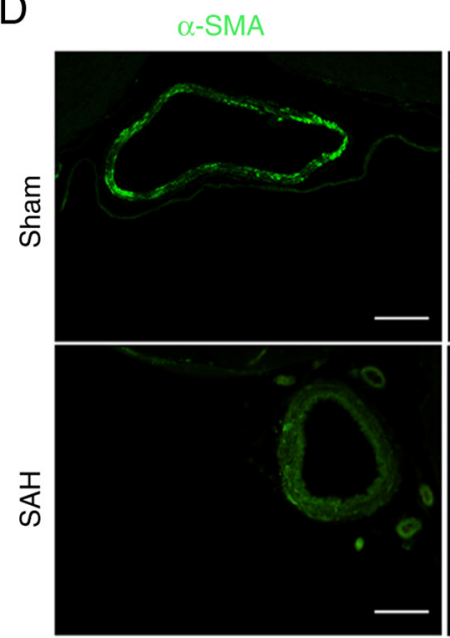

$\mathrm{B}$

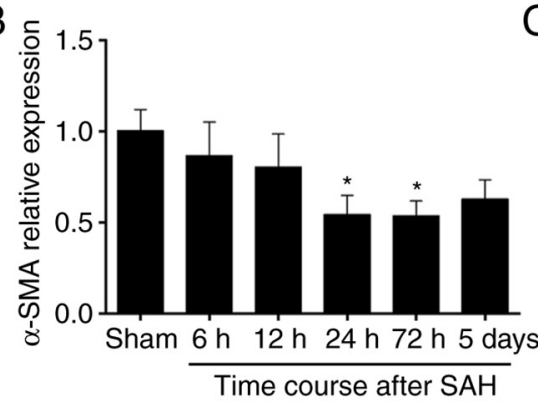

SMemb
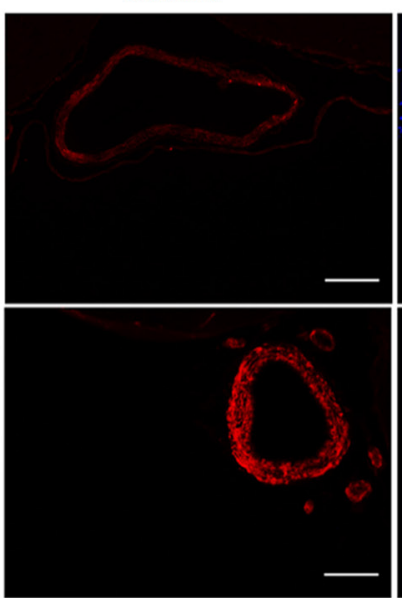

DAPI
C
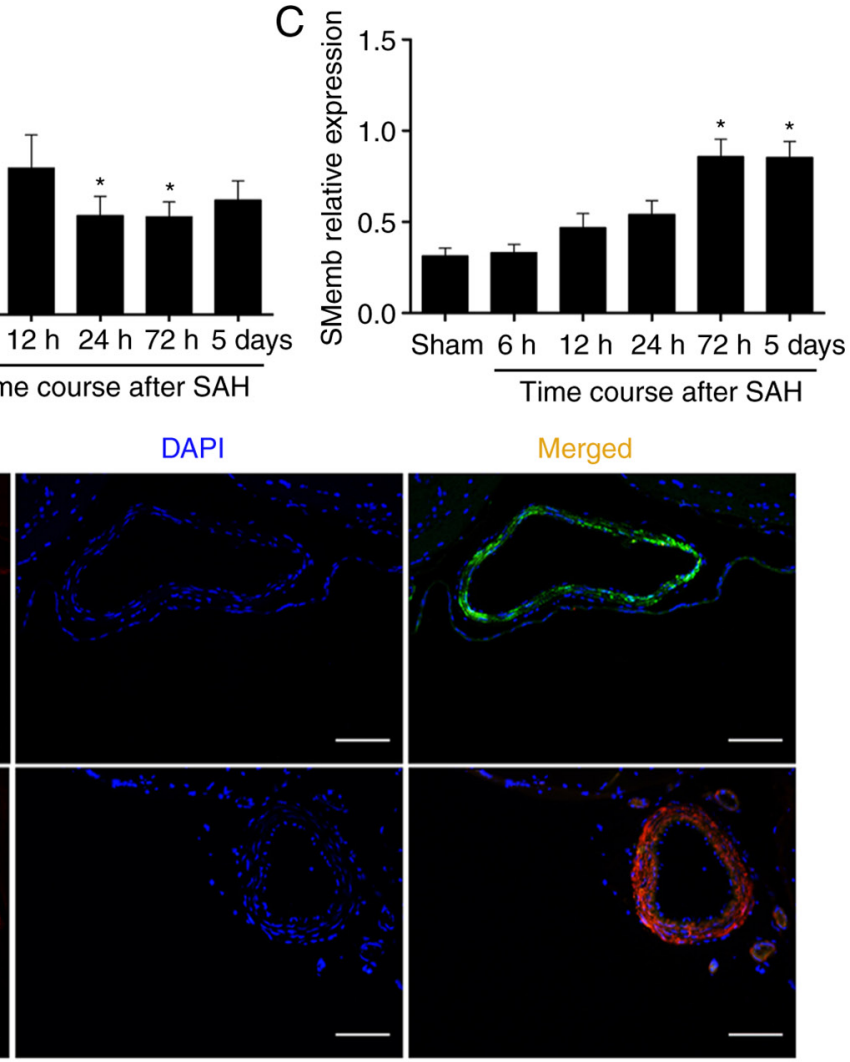

Merged
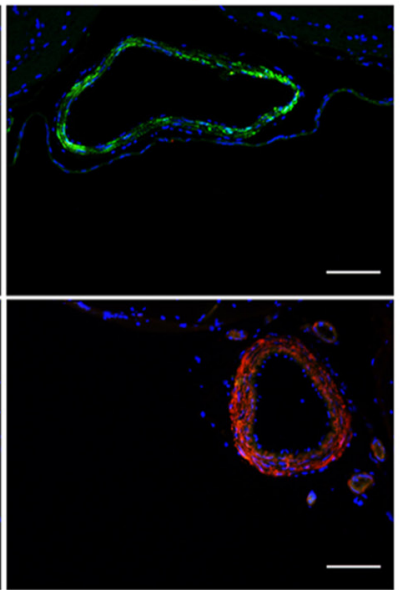

Figure 3. Expression profile of $\alpha$-SMA and SMemb. (A) Temporal profile of $\alpha$-SMA and SMemb expression in the cerebral vessels (n=6) and western blotting results showing that (B) $\alpha$-SMA expression was decreased as early as $6 \mathrm{~h}$. (C) SMemb level variations occurred as early as at $6 \mathrm{~h}$ and the expression was significantly increased at $72 \mathrm{~h}(\mathrm{n}=6)$. (D) Immunofluorescence analysis of basilar arteries with $\alpha$-SMA (green), SMemb (red) and DAPI (blue) at $72 \mathrm{~h}$ after SAH $(\mathrm{n}=4)$. Scale bar, $50 \mu \mathrm{m}$. ${ }^{*} \mathrm{P}<0.05$ vs. Sham. $\alpha$-SMA, $\alpha$-smooth muscle actin; SMemb, smooth muscle myosin heavy chain; SAH, subarachnoid hemorrhage.

compared with those of the Sham group (Fig. 7A and B) and Ad-PPAR $\beta / \delta$ pretreatment significantly decreased the brain wet weight and brain volume. Specifically, Ad-PPAR $\beta / \delta$ pretreatment markedly decreased the water content in the bilateral cerebral hemispheres and cerebellum at $72 \mathrm{~h}$, whereas treatment with Ad-GFP did not have the same effect (Fig. 7C). Additionally, the cerebral blood volume in the Ad-PPAR $\beta / \delta$ pretreatment group at $72 \mathrm{~h}$ was significantly lower than that of the SAH and SAH + Ad-GFP groups (Fig. 7D).

\section{Discussion}

VSMCs are highly plastic and their phenotypic switch is considered to be involved in the process of vessel remodeling $(11,39)$. The current study demonstrated that the Ad-PPAR $\beta / \delta$ ameliorated CVS and impeded VSMCs phenotypic transformation partially via suppression of ERK1/2 signaling pathway and was associated with decreased levels of p-Elk-1 and p-p90RSK. Furthermore, pre-administration of Ad-PPAR $\beta / \delta$ attenuated the brain volume, brain water content and blood volume at $72 \mathrm{~h}$ after SAH. Immunohistochemistry demonstrated that Ad-PPAR $\beta / \delta$ markedly increased the lumen diameter in the basilar arteries at $72 \mathrm{~h}$ after $\mathrm{SAH}$ and clearly improved the neurologic deficit. Overall, the findings suggested that the phenotypic conversion of VSMCs participated in the process of CVS following SAH and Ad-PPAR $\beta / \delta$ prevented VSMCs phenotypic transformation and attenuated CVS following $\mathrm{SAH}$ in rats via the ERK1/2 signaling pathway (Fig. 8).
A number of clinical studies have demonstrated that angiographically detectable CVS is observed in patients with SAH and it is hypothesized to be one of the most important considerations that contribute to the neurological impairment and lead to the increase of deformity and mortality following SAH $(40,41)$. Despite some achievements having been made in CVS research, the precise underlying mechanism remains to be elucidated. It has been reported that the phenotypic transition of VSMCs is considered to be one of the pathogenesis of CVS following SAH (42). VSMCs, which are an essential component of the cerebral vascular neural network, are involved in the pathophysiology of $\mathrm{SAH}$, as previously reported by Zhang et al (16) and subsequent studies have demonstrated that VSMCs undergoes phenotypic transformation under the conditions of local vascular inflammation or destruction and in the presence of toxic metabolites in the blood following SAH $(15,43)$. After transforming into synthetic cells, proliferation is abnormally increased and these cells exhibit high extracellular matrix proteins synthesis efficiency, ultimately leading to a decline in autoregulatory capacity $(15,44)$. The proliferative synthetic state of VSMCs has been shown to exert a pivotal role in the impairment of vascular regulation function and cerebral blood flow distribution $(15,44,45)$. The VSMC phenotypic switch leads to the loss of arteriolar autoregulation and influences the integrity of the blood-brain barrier (46). Due to these characteristics, VSMCs might be an alternative therapy target for CVS following SAH. In the present study, it was observed that the existence of VSMC 
A

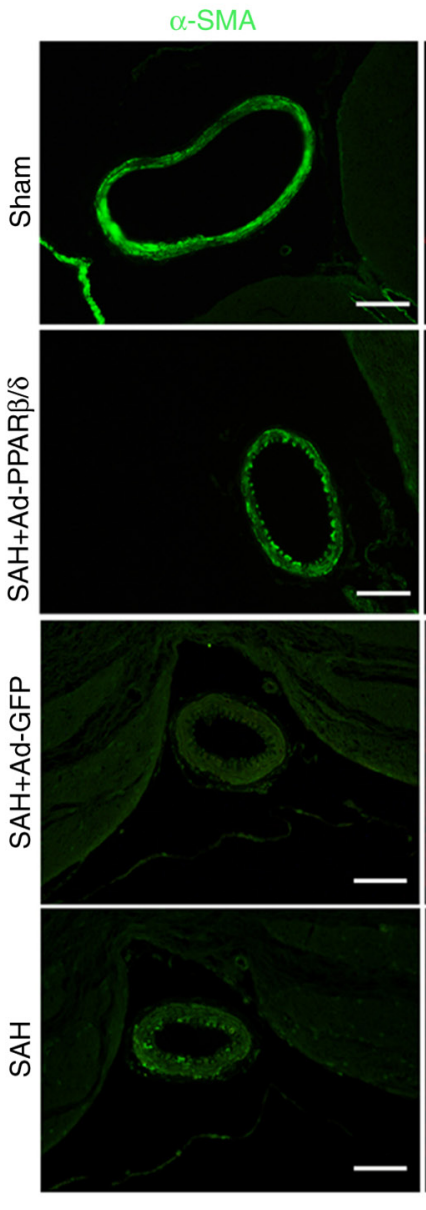

SMemb

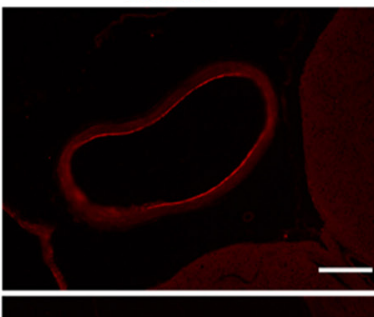

DAPI

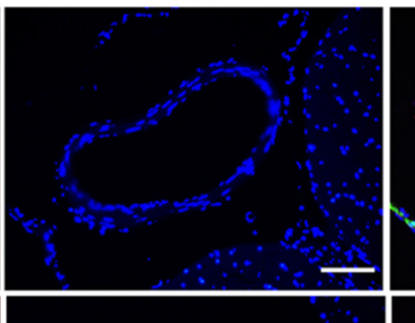

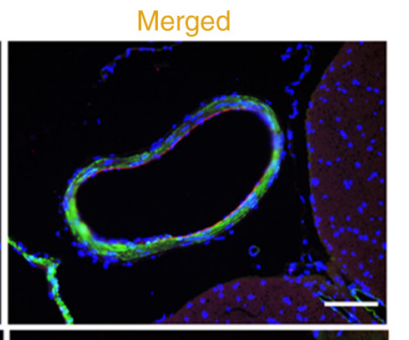

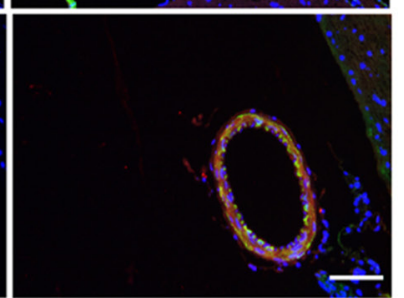

$\mathrm{B}$
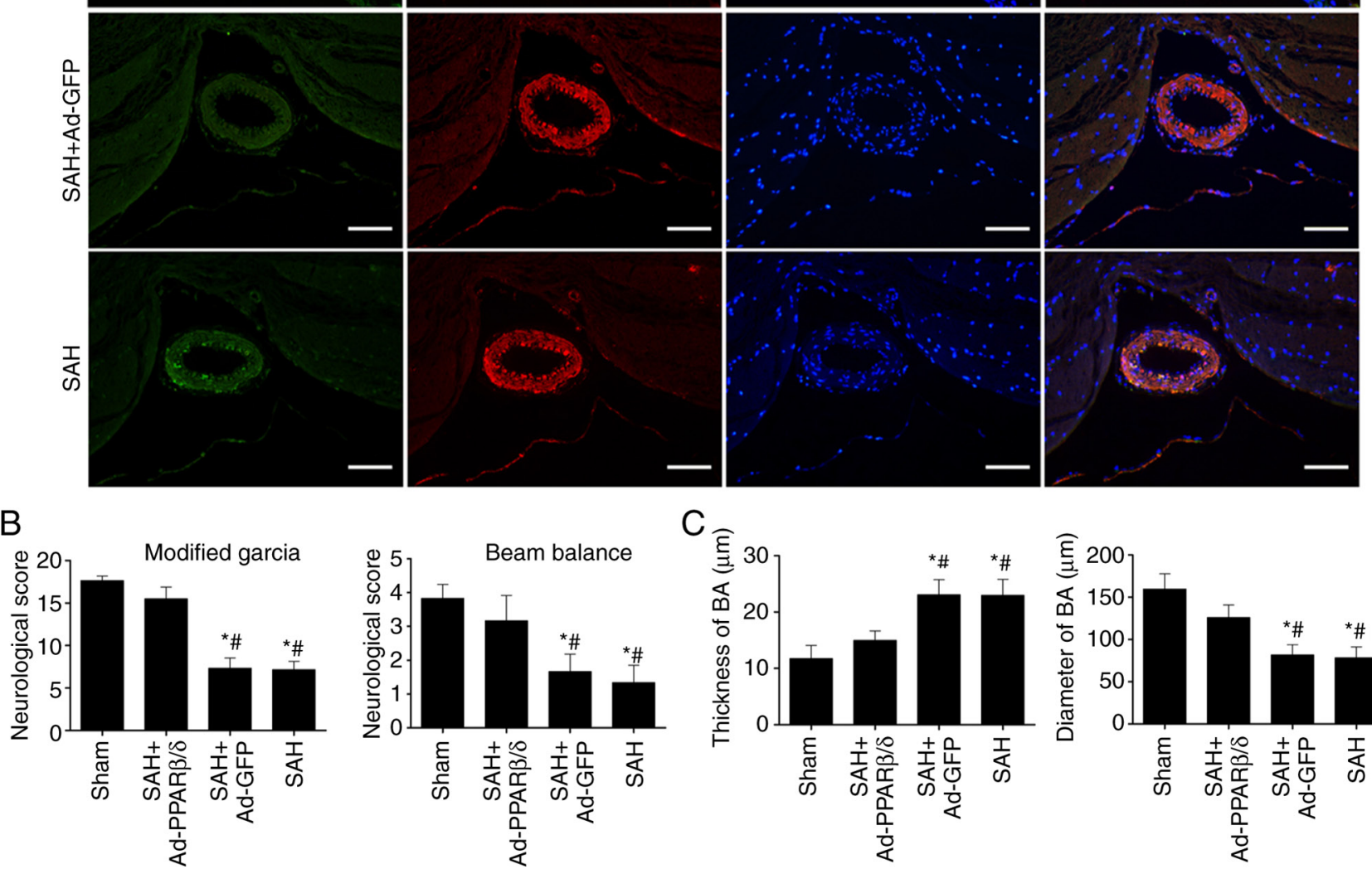

Figure 4. Overexpression of PPAR $\beta / \delta$ protein induced by Ad-PPAR $\beta / \delta$ improves the neurological deficits and attenuates cerebral vasospasm. (A) Immunofluorescence analysis of the BA with $\alpha$-SMA (green), SMemb (red) and DAPI (blue) at $72 \mathrm{~h}$ after SAH (n=6). Scale bar, $50 \mu \mathrm{m}$. (B) Rats in the SAH and SAH + Ad-GFP groups exhibited severe neurological impairments, while Ad-PPAR $\beta / \delta$ improved neurological impairments (n=6). (C) Histopathological alterations, including the thickness of the vascular wall and lumen stenosis in BA, were significantly ameliorated by Ad-PPAR $\beta / \delta(n=6)$. * $\mathrm{P}<0.05$ vs. Sham; ${ }^{\text {"P }}<0.05$ vs. SAH + Ad-PPAR $\beta / \delta$. PPAR $\beta / \delta$, peroxisome proliferator-activated receptor $\beta / \delta$; Ad, adenovirus; $\alpha$-SMA, $\alpha$-smooth muscle actin; SMemb, smooth muscle myosin heavy chain; SAH, subarachnoid hemorrhage; GFP, green fluorescent protein; BA, basilar artery.

phenotypic transformation caused stenosis of the basilar artery and increased the wall thickness in the setting of SAH and this result was in line with previous studies.

$\operatorname{PPAR} \beta / \delta$ is a member of the PPARs nuclear hormone receptor superfamily, which also includes $\operatorname{PPAR} \alpha, \operatorname{PPAR} \beta / \delta$ and PPAR $\gamma$, and is the most widely and highly expressed isotype in the central nervous system compared with PPAR $\alpha$ and PPAR $\gamma$ (19). PPAR $\beta / \delta$ is involved in regulating the transcription of numerous target genes, modulating vascular cell proliferation and the inflammatory process $(47,48)$. However, the mechanisms of PPAR $\beta / \delta$-dependent gene regulation are complex. A large number of inflammatory cytokines are released following $\mathrm{SAH}$ and may partially contribute to the decrease of PPAR $\beta / \delta$ expression (49). Additionally, our previous study demonstrated that PPAR $\beta / \delta$ expression decreases following $\mathrm{SAH}$; however, upregulated expression of PPAR $\beta / \delta$ markedly ameliorates the early inflammation reaction (32). A previous study reported that the PPAR $\beta / \delta$ exerts positive anti-inflammatory effects during the attenuation of neointimal hyperplasia by inhibiting VSMC proliferation and accelerating re-endothelization (50). These results indicate that the PPAR $\beta / \delta$ has the capability to maintain the stability of vascular. However, to the best of the authors' knowledge, there is no direct evidence showing that PPAR $\beta / \delta$ has positive effects 

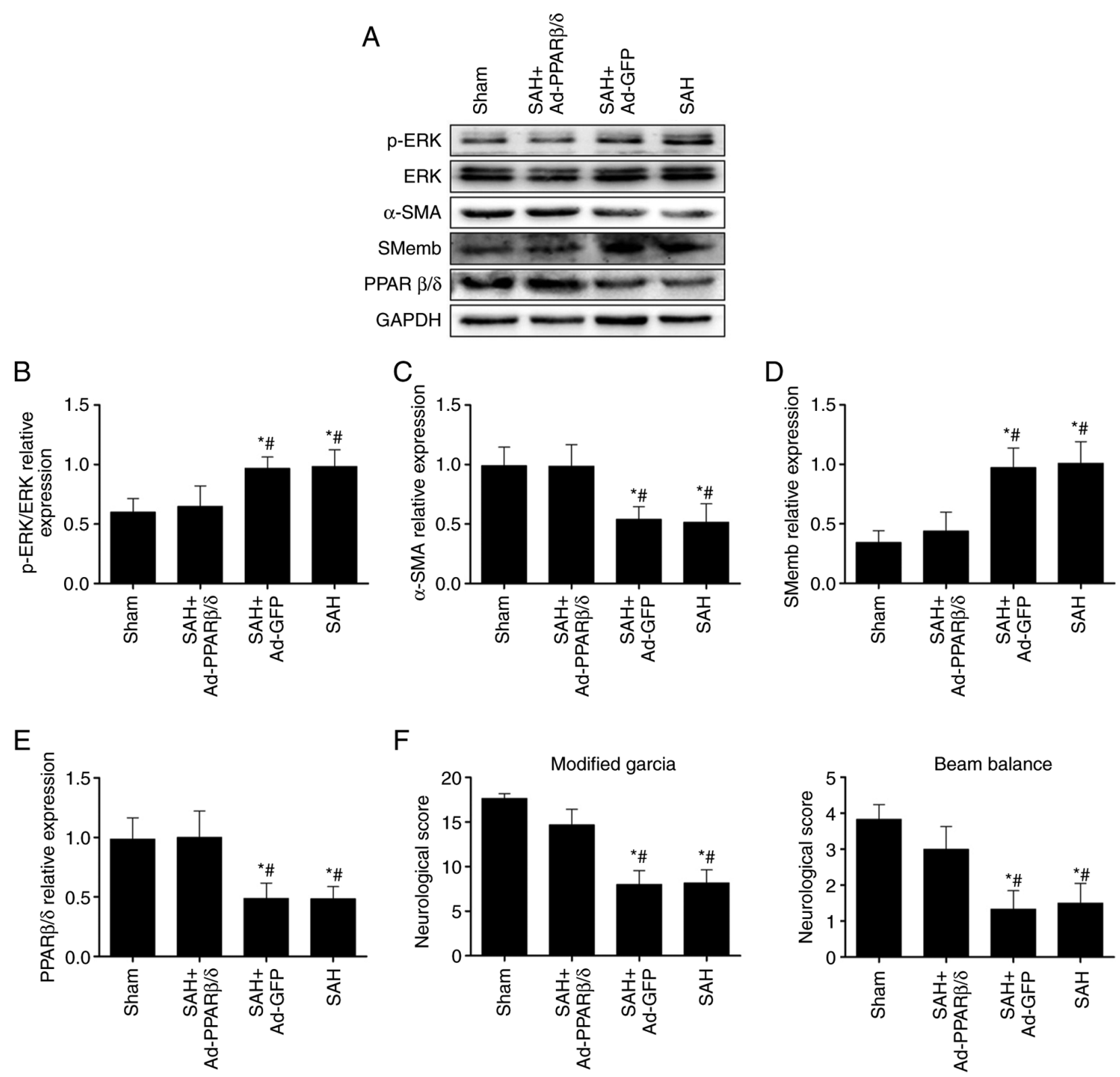

Figure 5. PPAR $\beta / \delta$ mediates vascular smooth muscle cell phenotypic changes and ameliorates cerebral vasospasm via ERK1/2 signaling. (A) Representative image of p-ERK/ERK ratio and $\alpha$-SMA, SMemb and PPAR $\beta / \delta$ expression in cerebral vessels at $72 \mathrm{~h}$ after SAH (n=6). (B-E) Expression levels of p-ERK and SMemb were significantly decreased by the pretreatment with Ad-PPAR $\beta / \delta$, while Ad-PPAR $\beta / \delta$ administration increased the PPAR $\beta / \delta$ and $\alpha$-SMA expression in cerebral vessels at $72 \mathrm{~h}$ after $\mathrm{SAH}(\mathrm{n}=6)$. (F) Ad-PPAR $\beta / \delta$ improved neurological impairments $(\mathrm{n}=6)$. ${ }^{*} \mathrm{P}<0.05$ vs. Sham; ${ }^{*} \mathrm{P}<0.05 \mathrm{vs}$. SAH + Ad-PPAR $\beta / \delta$, PPAR $\beta / \delta$, peroxisome proliferator-activated receptor $\beta / \delta$; -, phosphorylated; $\alpha$-SMA, $\alpha$-smooth muscle actin; SMemb, smooth muscle myosin heavy chain; SAH, subarachnoid hemorrhage; Ad, adenovirus; GFP, green fluorescent protein.

on modulating the VSMC phenotypic switch in the central nervous system. In the present study morphological examinations revealed that the phenotypic switch occurred in the vascular wall following SAH. Administration of Ad-PPAR $\beta / \delta$ could alleviate the neurological deficit and impeded VSMC phenotypic transformation and CVS.

It has been documented that the ternary complex formed by serum response factor (SRF) and its coactivator myocardin binds with cis-acting elements $\mathrm{CArG}$ in the nucleus to regulate VSMC differentiation and maintain the contractile phenotype $(51,52)$. Takata et al $(53)$ report that the PPAR $\beta / \delta$ exerts anti-inflammatory effects in rat vascular tissues via suppression of the ERK1/2 signaling pathway. In addition, PPAR $\beta / \delta$ prevents endoplasmic reticulum stress and inflammation in skeletal muscle cells by suppressing the ERK1/2 signaling pathway (54). These findings indicate that ERK1/2 signaling pathway may serve an important role in the regulation of VSMC phenotype transformation. Elk-1 and p90RSK are important targets of the MEK/ERK signaling pathway $(24,55)$, p-Elk-1 competitively displaces myocardin from SRF, leading to repression of VSMCs contractile genes (56) and p90RSK takes effect on phenotypic switch, cell differentiation by binding to signal transduction molecules, gene transcription factors (24). In the present study, the expression levels of p-ERK, p-Elk-1 and p-p90RSK were markedly increased at $72 \mathrm{~h}$ after SAH. However, prior injection of Ad-PPAR $\beta / \delta$ into cerebral ventricles significantly decreased the levels of p-ERK, p-Elk-1 and p-p90RSK and improved the neurological 
A

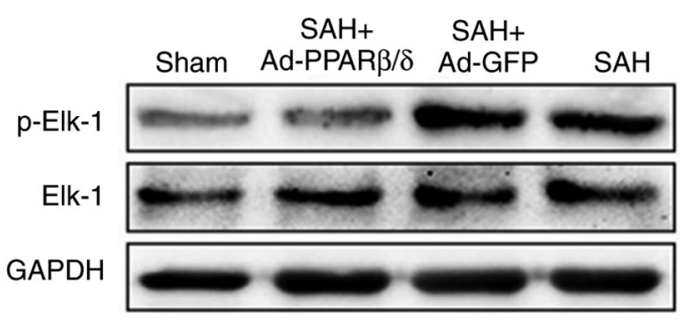

C

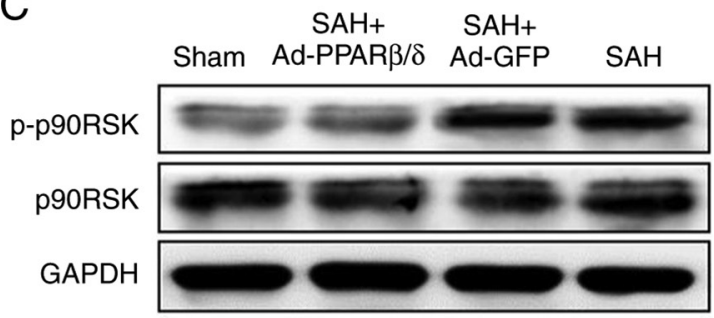

B

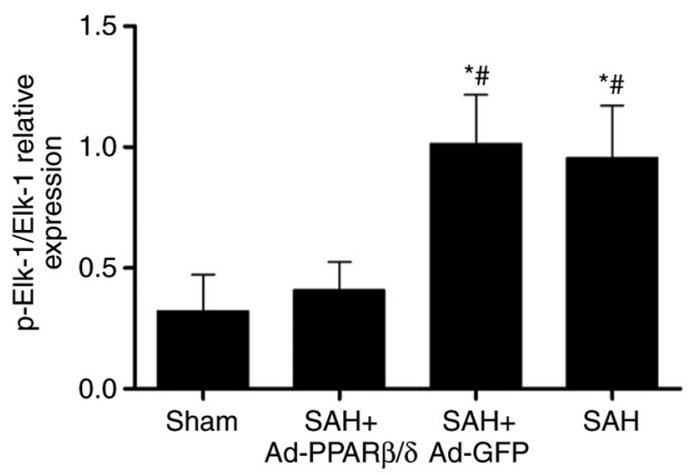

D

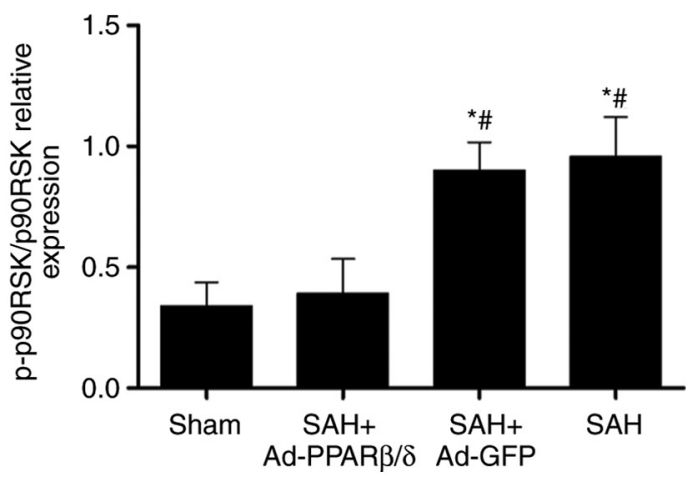

Figure 6. PPAR $\beta / \delta$ attenuates cerebral vascular smooth muscle cell phenotypic transformation by suppressing p-Elk-1 and p-p90RSK expression levels. Representative images of western blots showing (A) p-Elk-1 and (C) p-p90RSK protein expression in cerebral vessels at $72 \mathrm{~h}$ after SAH (n=6). Expression levels of (B) p-Elk-1 and (D) p-p90RSK were significantly downregulated by pretreatment with Ad-PPAR $\beta / \delta$ at $72 \mathrm{~h}$ after SAH ( $=6$ ). ${ }^{*}<0.05$ vs. Sham; ${ }^{\text {"}} \mathrm{P}<0.05$ vs. SAH + Ad-PPAR $\beta / \delta$. PPAR $\beta / \delta$, peroxisome proliferator-activated receptor $\beta / \delta$; $\mathrm{p}-$, phosphorylated; Ad, adenovirus; Elk-1, ETS domain-containing protein Elk-1; p90RSK, p90 ribosomal S6 kinase; SAH, subarachnoid hemorrhage; GFP, green fluorescent protein.
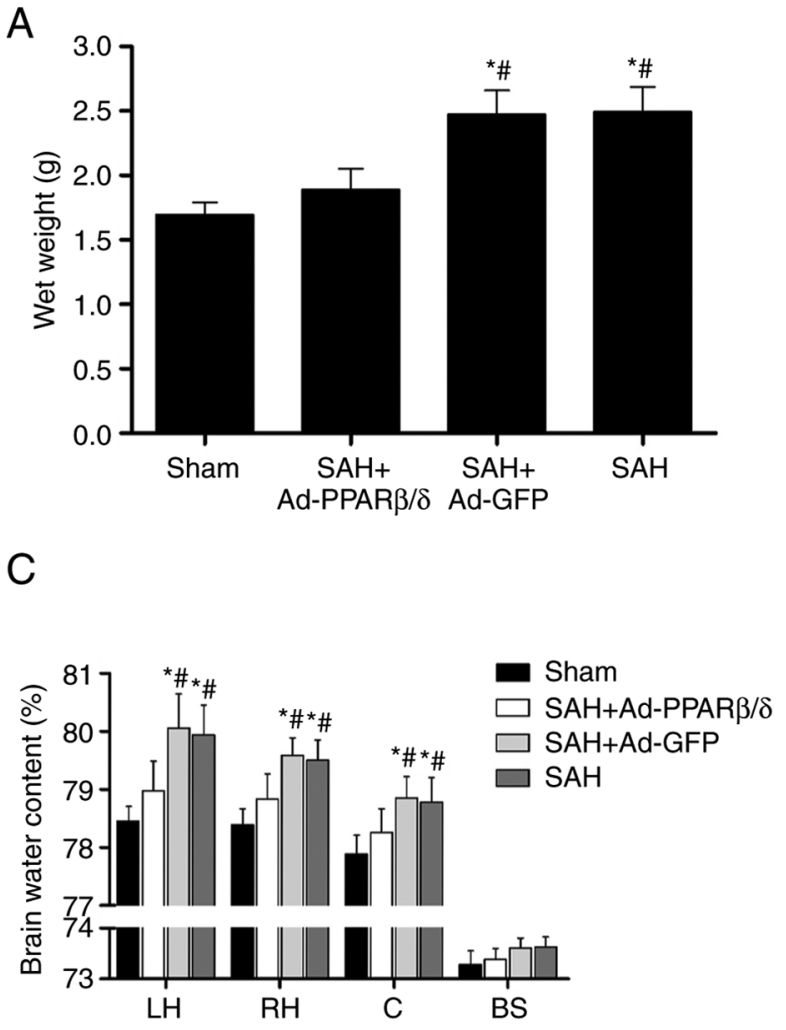
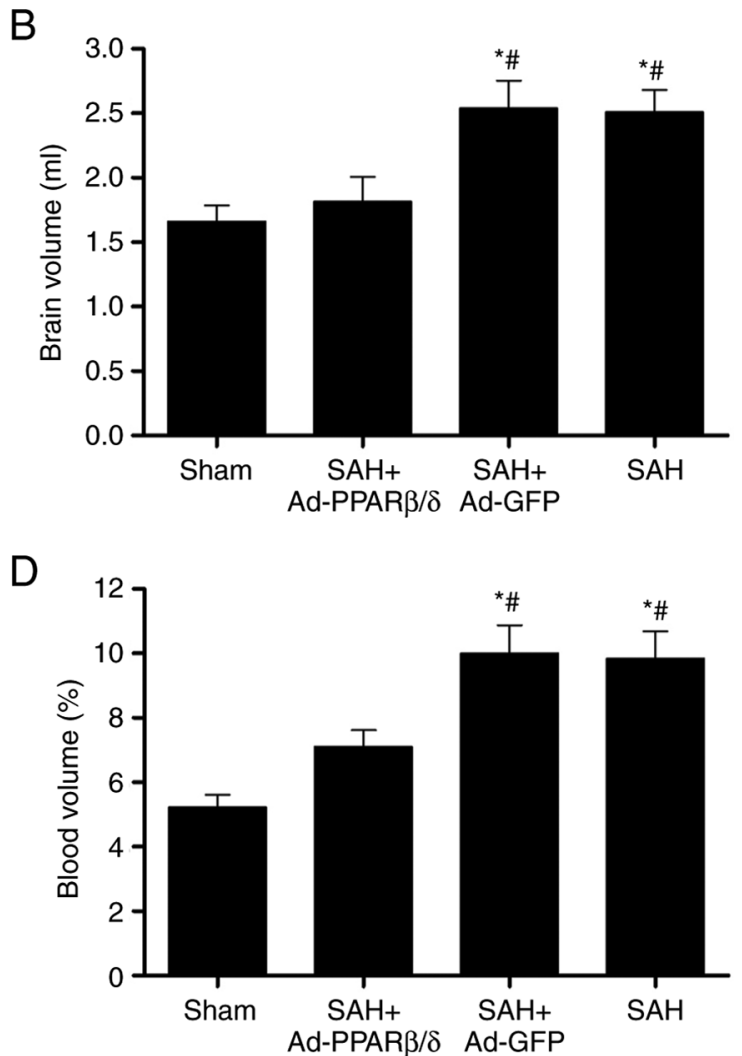

Figure 7. Intracerebroventricular injection of Ad-PPAR $\beta / \delta$ improves brain swelling and brain edema. Ad-PPAR $\beta / \delta$ pre-treatment decreased the $(A)$ brain wet weight, (B) brain volume, (C) brain water content and (D) blood volume at $72 \mathrm{~h}$ after $\mathrm{SAH}(\mathrm{n}=6)$. " $\mathrm{P}<0.05$ vs. Sham; "P<0.05 vs. SAH + Ad-PPAR $\beta / \delta$. Ad, adenovirus; PPAR $\beta / \delta$, peroxisome proliferator-activated receptor $\beta / \delta$; SAH, subarachnoid hemorrhage; LH, left hemisphere; RH, right hemisphere; C, cerebellum; BS, brain stem; GFP, green fluorescent protein. 


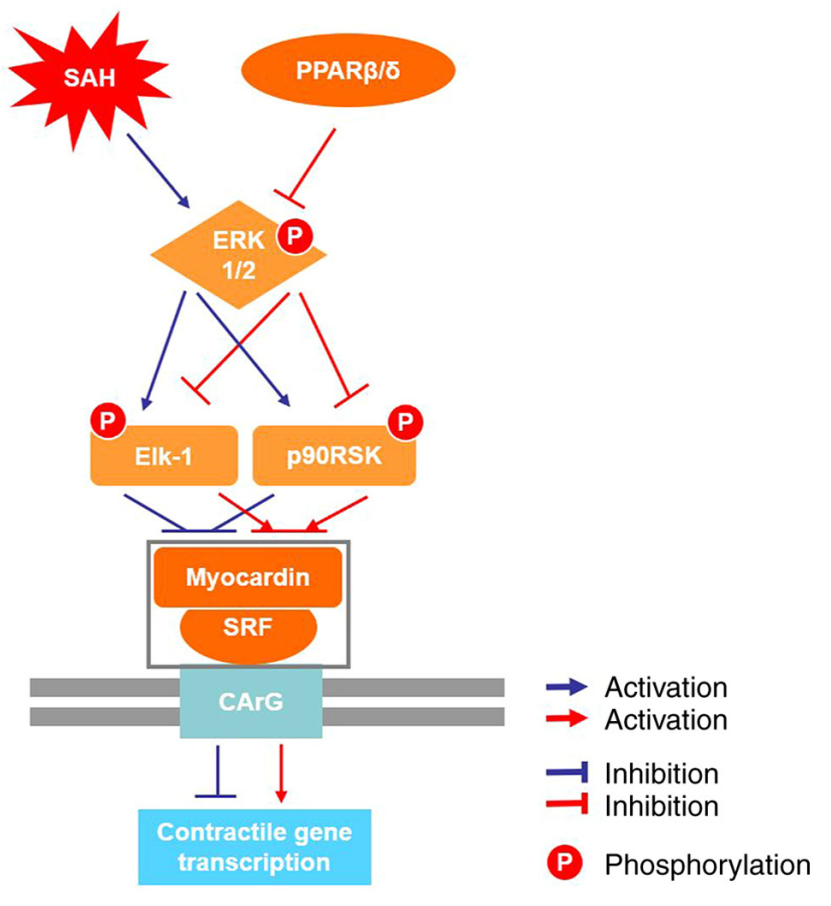

Figure 8. Proposed pathway in the present study. SAH, subarachnoid hemorrhage; PPAR $\beta / \delta$, peroxisome proliferator-activated receptor $\beta / \delta$; p-, phosphorylated; Elk-1, ETS domain-containing protein Elk-1; p90RSK, p90 ribosomal S6 kinase; SRF, serum response factor.

functions following SAH. These results revealed that PPAR $\beta / \delta$ modulates the phenotypic transformation of VSMCs following $\mathrm{SAH}$, at least partly, via inhibition of the ERK1/2 signaling pathway and expression of p-Elk-1 and p-p90RSK.

There are PPAR $\beta / \delta$ binding sites on the promoter of $\mathrm{NF}-\kappa \mathrm{B}$ and activator protein 1 (AP1) and PPAR $\beta / \delta$ binding to these promoters contribute to suppressing transcription of these target genes (57). In addition, it is reported that PPAR $\beta / \delta$ prevents TNF-a-induced $\mathrm{NF}-\kappa \mathrm{B}$ activation in human $\mathrm{HaCaT}$ cells through AMP-activated protein kinase (AMPK) and sirtuin1 (SIRT1) (58). In addition, it is reported that inactivation of $\mathrm{NF}-\kappa \mathrm{B}$ or AP1 leads to a decrease in p-ERK (59). Therefore, it was hypothesized that the PPAR $\beta / \delta$ suppressed p-ERK levels in a dual mode by directly binding to promoter of target gene and by inhibiting other possible potential signal pathways. However, the expression of $\mathrm{NF}-\kappa \mathrm{B}$ or AP1 were not detected, which is a limitation of the present study. Additional experiments should be conducted to investigate the potential mechanism of how PPAR $\beta / \delta$ regulates the ERK1/2 signaling pathway.

The PPAR $\gamma$ agonists rosiglitazone or troglitazone have been used to treat clinical diabetes mellitus and to study its effects, mainly in ischemic stroke, for a number of years. Activation of PPAR- $\gamma$ in VSMCs by the antidiabetic agent troglitazone (or rosiglitazone) inhibits VSMC proliferation and migration $(9,60)$. However, it is unclear whether these agonists can also activate PPAR $\beta / \delta$ and inhibit VSMC phenotypic transformation. Although the PPAR $\beta / \delta$ ligand L-165041 induces cell cycle arrest in VSMCs and inhibits their proliferation and migration (18), PPAR $\beta / \delta$ agonists are still in the preclinical research stage. Further studies are required to account for the beneficial mechanisms and to examine the effects of additional PPAR $\beta / \delta$ agonists. Nimodipine is the standard and main treatment of patients with aneurysmal $\mathrm{SAH}$ as it has been demonstrated to have a statistically significant beneficial impact on clinical outcome (61). Nimodipine prevents increases in intracellular calcium by blocking dihydropyridine sensitive (L-type) calcium channels (62), but its mechanism of effect in patients with SAH is unknown. It does not appear to reduce angiographically detectable CVS. This suggests that studies should focus more on inhibiting vascular pathological changes following SAH.

An increasing number of studies have explored the mechanisms of CVS following SAH, whereas the molecular mechanism underlying it remains largely speculative. Both basic and clinical researches focus on inflammation, disruption of blood-brain barrier, neuronal cell death, apoptosis, endothelial injury during in CVS course following SAH $(1,2,63)$. The cerebral vascular neural network, which includes VSMCs, is involved in the pathophysiology of SAH (16). In addition, other studies demonstrate that unbalanced contractile/synthetic VSMC phenotype affects the size of the cerebral arteries and alters brain swelling or cerebral edema $(44,45,64)$. To date, however, few studies have directly addressed the relationship between phenotype conversion of VSMCs and CVS. The present study focused on the vascular pathological changes induced by the phenotypic transformation of VSMCs following SAH due to its association with CVS. There is more widespread distribution and content of PPAR $\beta / \delta$ in the central nervous system (19), however little is known about the exact function of PPAR $\beta / \delta$ in central nervous system disease. Similarly, no direct evidence indicates that PPAR $\beta / \delta$ serves an active role in regulating the phenotypic transformation of VSMCs following SAH. The present authors have reported that PPAR $\beta / \delta$ inhibits hemoglobin-induced phenotypic transformation of cultured VSMCs in vitro (38). The present study mainly explored the mechanism of PPAR $\beta / \delta$ regulating VSMCs transformation and CVS through in vivo experiments to provide ideas for future clinical transformation research.

In conclusion, the present study demonstrated that the phenotypic transformation of VSMC was involved in the pathophysiology of CVS in experimental SAH, PPAR $\beta / \delta$ positively regulated VSMC phenotypic modulation and CVS, partly via suppression of ERK activation and downregulation of p-Elk-1 and p-p90RSK expression levels. Further studies should be implemented to evaluate whether PPAR $\beta / \delta$ would increase cerebral blood flow. The results of the present study may provide new evidence on the treatment of clinical vascular damage following SAH and clinical translation.

\section{Acknowledgements}

Not applicable.

\section{Funding}

The present study was supported by the National Natural Science Foundation for Youth of China (grant no. 81801137), the Jiangsu Provincial Medical Key Talent Grant (grant no. ZDRCA2016040) and a grant (grant no. SYS2019045) from the Suzhou Government. 


\section{Availability of data and materials}

All data generated or analyzed during this study are included in this published article.

\section{Authors' contributions}

$\mathrm{HZ}$ and CM designed the research protocols. LX and YL performed the experiments. JW, LX and GC analyzed the study data. LX and JW wrote the manuscript. HZ and CM confirm the authenticity of all the raw data. All authors have read and approved the final manuscript.

\section{Ethics approval and consent to participate}

All experimental procedures were approved by the Animal Experiments Ethic Committee at The First Affiliated Hospital of Soochow University (Suzhou, China; approval no. 2018-094).

\section{Patient consent for publication}

Not applicable.

\section{Competing interests}

The authors declare that they have no competing interests.

\section{References}

1. Pluta RM, Hansen-Schwartz J, Dreier J, Vajkoczy P, Macdonald RL, Nishizawa S, Kasuya H, Wellman G, Keller E, Zauner A, et al: Cerebral vasospasm following subarachnoid hemorrhage: Time for a new world of thought. Neurol Res 31: 151-158, 2009.

2. Chen S, Feng H, Sherchan P, Klebe D, Zhao G, Sun X, Zhang J, Tang $\mathbf{J}$ and Zhang JH: Controversies and evolving new mechanisms in subarachnoid hemorrhage. Prog Neurobiol 115: 64-91, 2014.

3. Rothoerl RD and Ringel F: Molecular mechanisms of cerebral vasospasm following aneurysmal SAH. Neurol Res 29: 636-642, 2007.

4. Ciurea AV, Palade C, Voinescu D and Nica DA: Subarachnoid hemorrhage and cerebral vasospasm-literature review. J Med Life 6: 120-125, 2013.

5. Crowley RW, Medel R, Kassell NF and Dumont AS: New insights into the causes and therapy of cerebral vasospasm following subarachnoid hemorrhage. Drug Discov Today 13: 254-260, 2008.

6. Fassbender K, Hodapp B, Rossol S, Bertsch T, Schmeck J, Schütt S, Fritzinger M, Horn P, Vajkoczy P, Kreisel S, et al: Inflammatory cytokines in subarachnoid hemorrhage: Association with abnormal blood flow velocities in basal cerebral arteries. J Neurol Neurosurg Psychiatry 70: 534-537, 2001.

7. Osuka K, Watanabe Y, Yamauchi K, Nakazawa A, Usuda N, Tokuda M and Yoshida J: Activation of the JAK-STAT signaling pathway in the rat basilar artery after subarachnoid hemorrhage. Brain Res 1072: 1-7, 2006.

8. Dumont AS, Dumont RJ, Chow MM, Lin CL, Calisaneller T, Ley KF, Kassell NF and Lee KS: Cerebral vasospasm after subarachnoid hemorrhage: Putative role of inflammation. Neurosurgery 53: 123-135, 2003.

9. Cheng MF, Song JN, Li DD, Zhao YL, An JY, Sun P and Luo XH: The role of rosiglitazone in the proliferation of vascular smooth muscle cells after experimental subarachnoid hemorrhage. Acta Neurochir (Wien) 156: 2103-2109, 2014.

10. Kolias AG, Sen J and Belli A: Pathogenesis of cerebral vasospasm following aneurysmal subarachnoid hemorrhage: Putative mechanisms and novel approaches. J Neurosci Res 87: 1-11, 2009.
11. Ohkuma H, Tsurutani H and Suzuki S: Changes of beta-actin mRNA expression in canine vasospastic basilar artery after experimental subarachnoid hemorrhage. Neurosci Lett 311: 9-12, 2001.

12. Davis-Dusenbery BN, Wu C and Hata A: Micromanaging vascular smooth muscle cell differentiation and phenotypic modulation. Arterioscler Thromb Vasc Biol 31: 2370-2377, 2011.

13. Rensen SS, Doevendans PA and van Eys GJ: Regulation and characteristics of vascular smooth muscle cell phenotypic diversity. Neth Heart J 15: 100-108, 2007.

14. Beamish JA, He P, Kottke-Marchant K and Marchant RE: Molecular regulation of contractile smooth muscle cell phenotype: Implications for vascular tissue engineering. Tissue Eng Part B Rev 16: 467-491, 2010.

15. Shimamura $\mathrm{N}$ and Ohkuma H: Phenotypic transformation of smooth muscle in vasospasm after aneurysmal subarachnoid hemorrhage. Transl Stroke Res 5: 357-364, 2014.

16. Zhang JH, Badaut J, Tang J, Obenaus A, Hartman R and Pearce WJ: The vascular neural network-a new paradigm in stroke pathophysiology. Nat Rev Neurol 8: 711-716, 2012.

17. Zhang J, Wang L, Fu W, Wang C, Guo D, Jiang J and Wang Y: Smooth muscle cell phenotypic diversity between dissected and unaffected thoracic aortic media. J Cardiovasc Surg (Torino) 54: 511-521, 2013.

18. Lim HJ, Lee S, Park JH, Lee KS, Choi HE, Chung KS, Lee HH and Park HY: PPAR delta agonist L-165041 inhibits rat vascular smooth muscle cell proliferation and migration via inhibition of cell cycle. Atherosclerosis 202: 446-454, 2009.

19. Moreno S, Farioli-Vecchioli S and Cerù MP: Immunolocalization of peroxisome proliferator-activated receptors and retinoid $\mathrm{X}$ receptors in the adult rat CNS. Neuroscience 123: 131-145, 2004.

20. Ehrenborg E and Krook A: Regulation of skeletal muscle physiology and metabolism by peroxisome proliferator-activated receptor delta. Pharmacol Rev 61: 373-393, 2009.

21. Kim HJ, Ham SA, Kim SU, Hwang JY, Kim JH, Chang KC, Yabe-Nishimura C, Kim JH and Seo HG: Transforming growth factor-betal is a molecular target for the peroxisome proliferator-activated receptor delta. Circ Res 102: 193-200, 2008.

22. Blenis J: Signal transduction via the MAP kinases: Proceed at your own RSK. Proc Natl Acad Sci USA 90: 5889-5892, 1993.

23. Seger R and Krebs EG: The MAPK signaling cascade. FASEB J 9: 726-735, 1995.

24. Frödin $\mathrm{M}$ and Gammeltoft S: Role and regulation of $90 \mathrm{kDa}$ ribosomal S6 kinase (RSK) in signal transduction. Mol Cell Endocrinol 151: 65-77, 1999.

25. Kawai-Kowase K and Owens GK: Multiple repressor pathways contribute to phenotypic switching of vascular smooth muscle cells. Am J Physiol Cell Physiol 292: C59-C69, 2007.

26. Kang YH, Yang IJ and Shin HM: Herbal formula HMC05 prevents human aortic smooth muscle cell migration and proliferation by inhibiting the ERK1/2 MAPK signaling cascade. J Nat Med 66: 177-184, 2012.

27. MacArthur Clark JA and Sun D: Guidelines for the ethical review of laboratory animal welfare People's Republic of China national standard GB/T 35892-2018 (issued 6 February 2018 effective from 1 September 2018). Animal Model Exp Med 3: 103-113, 2020.

28. Muroi C, Fujioka M, Okuchi K, Fandino J, Keller E, Sakamoto Y, Mishima K, Iwasaki K and Fujiwara M: Filament perforation model for mouse subarachnoid hemorrhage: Surgical-technical considerations. Br J Neurosurg 28: 722-732, 2014.

29. Sugawara T, Ayer R, Jadhav V and Zhang JH: A new grading system evaluating bleeding scale in filament perforation subarachnoid hemorrhage rat model. J Neurosci Methods 167: 327-334, 2008.

30. Suzuki H, Hasegawa Y, Chen W, Kanamaru K and Zhang JH: Recombinant osteopontin in cerebral vasospasm after subarachnoid hemorrhage. Ann Neurol 68: 650-660, 2010.

31. Chen Y, Zhang Y, Tang J, Liu F, Hu Q, Luo C, Tang J, Feng H and Zhang JH: Norrin protected blood-brain barrier via frizzled-4/ $\beta$-catenin pathway after subarachnoid hemorrhage in rats. Stroke 46: 529-536, 2015.

32. Teng Z, Jiang L, Hu Q, He Y, Guo Z, Wu Y, Huang Z, Cao F, Cheng C, Sun X and Guo Z: Peroxisome proliferator-activated receptor $\beta / \delta$ alleviates early brain injury after subarachnoid hemorrhage in rats. Stroke 47: 196-205, 2016.

33. Ostrowski RP, Colohan AR and Zhang JH: Mechanisms of hyperbaric oxygen-induced neuroprotection in a rat model of subarachnoid hemorrhage. J Cereb Blood Flow Metab 25: 554-571, 2005. 
34. Choudhri TF, Hoh BL, Solomon RA, Connolly ES Jr and Pinsky DJ: Use of a spectrophotometric hemoglobin assay to objectively quantify intracerebral hemorrhage in mice. Stroke 28: 2296-2302, 1997.

35. Carpenter RC, Miao L, Miyagi Y, Bengten E and Zhang JH: Altered expression of $\mathrm{P}(2)$ receptor mRNAs in the basilar artery in a rat double hemorrhage model. Stroke 32: 516-522, 2001.

36. Chen D, Tang J, Khatibi NH, Zhu M, Li Y, Wang C, Jiang R, Tu L and Wang S: Treatment with Z-ligustilide, a component of Angelica sinensis, reduces brain injury after a subarachnoid hemorrhage in rats. J Pharmacol Exp Ther 337: 663-672, 2011.

37. Fan R, Enkhjargal B, Camara R, Yan F, Gong L, ShengtaoYao, Tang J, Chen Y and Zhang JH: Critical role of EphA4 in early brain injury after subarachnoid hemorrhage in rat. Exp Neurol 296: 41-48, 2017.

38. Zhang H, Jiang L, Guo Z, Zhong J, Wu J, He J, Liu H, He Z, $\mathrm{Wu} \mathrm{H}$, Cheng $\mathrm{C}$ and Sun X: PPAR $\beta / \delta$, a novel regulator for vascular smooth muscle cells phenotypic modulation and vascular remodeling after subarachnoid hemorrhage in rats. Sci Rep 7: 45234, 2017.

39. Maddahi A, Povlsen GK and Edvinsson L: Regulation of enhanced cerebrovascular expression of proinflammatory mediators in experimental subarachnoid hemorrhage via the mitogen-activated protein kinase kinase/extracellular signal-regulated kinase pathway. J Neuroinflammation 9: 274, 2012.

40. Danura H, Schatlo B, Marbacher S, Kerkeni H, Diepers M, Remonda L, Fathi AR and Fandino J: Acute angiographic vasospasm and the incidence of delayed cerebral vasospasm: Preliminary results. Acta Neurochir Suppl 120: 187-190, 2015.

41. Shimamura N, Munakata A and Ohkuma H: Current management of subarachnoid hemorrhage in advanced age. Acta Neurochir Suppl 110: 151-155, 2011.

42. Chou SH, Smith EE, Badjatia N, Nogueira RG, Sims JR II, Ogilvy CS, Rordorf GA and Ayata C: A randomized, double-blind, placebo-controlled pilot study of simvastatin in aneurysmal subarachnoid hemorrhage. Stroke 39: 2891-2893, 2008.

43. Edvinsson LI and Povlsen GK: Vascular plasticity in cerebrovascular disorders. J Cereb Blood Flow Metab 31: 1554-1571, 2011.

44. Ohkuma H, Suzuki S and Ogane K: Phenotypic modulation of smooth muscle cells and vascular remodeling in intraparenchymal small cerebral arteries after canine experimental subarachnoid hemorrhage. Neurosci Lett 344: 193-196, 2003.

45. Wu J, Zhang Y, Yang P, Enkhjargal B, Manaenko A, Tang J, Pearce WJ, Hartman R, Obenaus A, Chen G and Zhang JH: Recombinant osteopontin stabilizes smooth muscle cell phenotype via integrin receptor/integrin-linked kinase/rac-1 pathway after subarachnoid hemorrhage in rats. Stroke 47: 1319-1327, 2016.

46. Smyth LCD, Rustenhoven J, Scotter EL, Schweder P, Faull RL, Park TI and Dragunow M: Markers for human brain pericytes and smooth muscle cells. J Chem Neuroanat 92: 48-60, 2018.

47. Piqueras L, Reynolds AR, Hodivala-Dilke KM, Alfranca A, Redondo JM, Hatae T, Tanabe T, Warner TD and Bishop-Bailey D: Activation of PPARbeta/delta induces endothelial cell proliferation and angiogenesis. Arterioscler Thromb Vasc Biol 27: 63-69, 2007.

48. Lee CH, Chawla A, Urbiztondo N, Liao D, Boisvert WA, Evans RM and Curtiss LK: Transcriptional repression of atherogenic inflammation: Modulation by PPARdelta. Science 302: 453-457, 2003

49. Chang CZ, Wu SC and Kwan AL: Glycyrrhizin attenuates proinflammatory cy tokines through a peroxisome proliferator-activated receptor- $\gamma$-dependent mechanism and experimental vasospasm in a rat model. J Vasc Res 52: 12-21, 2015.
50. Hamaya R, Ogawa M, Suzuki J, Kobayashi N, Hirata Y, Nagai R, Komuro I and Isobe M: A selective peroxisome proliferator-activated receptor- $\beta / \delta$ agonist attenuates neointimal hyperplasia after wire-mediated arterial injury. Expert Opin. Investig. Drugs 22: 1095-1106, 2013.

51. Pipes GC, Creemers EE and Olson EN: The myocardin family of transcriptional coactivators: Versatile regulators of cell growth, migration, and myogenesis. Genes Dev 20: 1545-1556, 2006.

52. Parmacek MS: Myocardin-related transcription factors: Critical coactivators regulating cardiovascular development and adaptation. Circ Res 100: 633-644, 2007.

53. Takata Y, Liu J, Yin F, Collins AR, Lyon CJ, Lee CH, Atkins AR, Downes M, Barish GD, Evans RM, et al: PPARdelta-mediated antiinflammatory mechanisms inhibit angiotensin II-accelerated atherosclerosis. Proc Natl Acad Sci USA 105: 4277-4282, 2008.

54. Salvadó L, Barroso E, Gómez-Foix AM, Palomer X, Michalik L, Wahli W and Vázquez-Carrera M: PPAR $\beta / \delta$ prevents endoplasmic reticulum stress-associated inflammation and insulin resistance in skeletal muscle cells through an AMPK-dependent mechanism. Diabetologia 57: 2126-2135, 2014.

55. Hsieh HL, Wu CY and Yang CM: Bradykinin induces matrix metalloproteinase-9 expression and cell migration through a PKC-delta-dependent ERK/Elk-1 pathway in astrocytes. Glia 56: 619-632, 2008

56. Wang Z, Wang DZ, Hockemeyer D, McAnally J, Nordheim A and Olson EN: Myocardin and ternary complex factors compete for SRF to control smooth muscle gene expression. Nature 428: 185-189, 2004

57. Toral M, Romero M, Pérez-Vizcaíno F, Duarte J and Jiménez R: Antihypertensive effects of peroxisome proliferator-activated receptor- $\beta / \delta$ activation. Am J Physiol Heart Circ Physiol 312: H189-H200, 2017.

58. Barroso E, Eyre E, Palomer X and Vázquez-Carrera M: The peroxisome proliferator-activated receptor $\beta / \delta(\operatorname{PPAR} \beta / \delta)$ agonist GW501516 prevents TNF- $\alpha$-induced NF- $\kappa$ B activation in human $\mathrm{HaCaT}$ cells by reducing p65 acetylation through AMPK and SIRT1. Biochem Pharmacol 81: 534-543, 2011.

59. Zarzuelo MJ, Jiménez R, Galindo P, Sánchez M, Nieto A, Romero M,Quintela AM,López-Sepúlveda R,Gómez-Guzmán M, Bailón E, et al: Antihypertensive effects of peroxisome proliferator-activated receptor- $\beta$ activation in spontaneously hypertensive rats. Hypertension 58: 733-743, 2011.

60. Law RE, Goetze S, Xi XP, Jackson S, Kawano Y, Demer L, Fishbein MC, Meehan WP and Hsueh WA: Expression and function of PPARgamma in rat and human vascular smooth muscle cells. Circulation 101: 1311-1318, 2000.

61. Dorhout Mees SM, Rinkel GJE, Feigin VL, Algra A, van den Bergh WM, Vermeulen M and van Gijn J: Calcium antagonists for aneurysmal subarachnoid hemorrhage. Stroke 39: 514-515, 2008.

62. Pandey AS, Elias AE, Chaudhary N, Thompson BG and Gemmete JJ: Endovascular treatment of cerebral vasospasm: Vasodilators and angioplasty. Neuroimaging Clin N Am 23: 593-604, 2013

63. Hansen-Schwartz J: Cerebral vasospasm: A consideration of the various cellular mechanisms involved in the pathophysiology. Neurocrit Care 1: 235-246, 2004.

64. Edvinsson L, Larsen SS, Maddahi A and Nielsen J: Plasticity of cerebrovascular smooth muscle cells after subarachnoid hemorrhage. Transl Stroke Res 5: 365-376, 2014.

This work is licensed under a Creative Commons Attribution-NonCommercial-NoDerivatives 4.0 International (CC BY-NC-ND 4.0) License. 